\title{
Metal-organic chemical vapour deposition of lithium manganese oxide thin films via single solid source precursor
}

\author{
K.O. Oyedotun ${ }^{1}$, E. Ajenifuja ${ }^{2 *}$, B. Olofinjana ${ }^{1}$, B.A. Taleatu ${ }^{1,3}$, E. Omotoso ${ }^{1}$, \\ M.A. Eleruja ${ }^{1}$, E.O.B. Ajay ${ }^{1}$ \\ ${ }^{1}$ Department of Physics, Obafemi Awolowo University, Ile-Ife, Nigeria \\ ${ }^{2}$ Centre for Energy Research and Development, Obafemi Awolowo University, Ile-Ife, Nigeria. \\ ${ }^{3}$ School of Chemistry and Physics, University of KwaZulu Natal Pietermaritzburg, P Bag X01 Scottsville 3209, South Africa \\ Lithium manganese oxide thin films were deposited on sodalime glass substrates by metal organic chemical vapour de- \\ position (MOCVD) technique. The films were prepared by pyrolysis of lithium manganese acetylacetonate precursor at a \\ temperature of $420{ }^{\circ} \mathrm{C}$ with a flow rate of $2.5 \mathrm{dm}^{3} / \mathrm{min}$ for two-hour deposition period. Rutherford backscattering spectroscopy \\ (RBS), UV-Vis spectrophotometry, X-ray diffraction (XRD) spectroscopy, atomic force microscopy (AFM) and van der Pauw \\ four point probe method were used for characterizations of the film samples. RBS studies of the films revealed fair thickness of \\ $1112.311\left(10^{15}\right.$ atoms $\left./ \mathrm{cm}^{2}\right)$ and effective stoichiometric relationship of $\mathrm{Li}_{0.47} \mathrm{Mn}_{0.27} \mathrm{O}_{0.26}$. The films exhibited relatively high \\ transmission $(50 \% \mathrm{~T})$ in the visible and NIR range, with the bandgap energy of $2.55 \mathrm{eV}$. Broad and diffused X-ray diffraction \\ patterns obtained showed that the film was amorphous in nature, while microstructural studies indicated dense and uniformly \\ distributed layer across the substrate. Resistivity value of $4.9 \Omega \cdot \mathrm{cm}$ was obtained for the thin film. Compared with $\mathrm{Mn}_{0.2} \mathrm{O}_{0.8}$ \\ thin film, a significant lattice absorption edge shift was observed in the $\mathrm{Li}_{0.47} \mathrm{Mn}_{0.27} \mathrm{O}_{0.26}$ film.
}

Keywords: $M O C V D$; thin film; pyrolysis; $\mathrm{Li}_{0.47} \mathrm{Mn}_{0.27} \mathrm{O}_{0.26}$; Rutherford backscattering; bandgap energy

(C) Wroclaw University of Technology.

\section{Introduction}

Numerous studies have shown the significance and popularity of thin film deposition technologies in the preparation of functional materials at micro and nano-dimensional layers, and this has invariably led to the emergence of various film deposition techniques, such as sputtering, electron beam evaporation, pulsed laser deposition, chemical vapour deposition, etc. Most thin film preparation techniques require high operational cost since they usually work at elevated temperature $[1,2]$, high vacuum and involve highly sophisticated instrumentations. However, metal organic thin films with controlled morphology and stoichiometry, already built-in during the precursor synthesis, can be prepared using relatively simple and cost effective metal organic chemical vapour deposition (MOCVD) method [3]. Using this technique,

*E-mail: eajenifuja@gmail.com deposition occurs at lower temperature and, unlike dip coating and chemical bath techniques, the substrate is not attacked chemically $[4,5]$.

Lithium-transition metal oxides are widely used for the cathode materials in solid state power sources. Transition metal oxides, such as $\mathrm{TiO}_{2}$, $\mathrm{MnO}, \mathrm{MnO}_{2}, \mathrm{CoO}_{2}$ [6-8], have been modified with lithium ion due to their microstructural properties to achieve high charge storage capacity and excellent recharge ability. Based on their other numerous applications besides being used as cathode materials, there has been a renewed interest in the studies of the properties of modified manganese oxide thin films. Such uses include efficient energy conversion systems, transparent electrodes in solar cells, optoelectronic display devices, and many other high technology systems [9]. Lithium manganese based cathodes and other functional materials are cheaper and environmentally friendlier [10]. Presently, the main applications of Li-ion batteries are for laptop computers and cellular phones. The 
intercalation of lithium into transition metal oxides and sulphides produces materials with structural stability that give rise to excellent electrochemical stability after a long period of cycling, thus, intercalation and de-intercalation of lithium ions has been utilized in the manufacture of lithiumion based power sources $[11,12]$. In this study, we report the preparation, chemical, microstructural and optical characterizations of lithium manganese oxide thin films on soda-lime glass from laboratory synthesized lithium manganese acetylacetonate precursor using low cost metal organic chemical vapour deposition (MOCVD) technique.

\section{Experimental}

\subsection{Preparation and characterization of the precursor}

Lithium manganese acetylacetonate precursor was prepared by adding slowly $40.0 \mathrm{~mL}$ of acetyl acetone to a solution of $16.0 \mathrm{~g}(0.3 \mathrm{~mol})$ of $\mathrm{NaOH}$ in $150.0 \mathrm{~mL}$ of water and kept at a temperature below $40{ }^{\circ} \mathrm{C}$ as shown in equation 1 :

$$
\mathrm{HC}_{5} \mathrm{H}_{7} \mathrm{O}_{2}+\mathrm{NaOH} \rightarrow \mathrm{NaC}_{5} \mathrm{H}_{7} \mathrm{O}_{2}+\mathrm{H}_{2} \mathrm{O}
$$

Lithium hydroxide, being hygroscopic in nature was heated gently to about $111{ }^{\circ} \mathrm{C}$ to a constant weight to remove the absorbed moisture. The yellowish solution containing acetylacetonate and $\mathrm{NaOH}$ was then added dropwise to $3.95 \mathrm{~g}$ $(0.02 \mathrm{~mol})$ of $\mathrm{MnCl}_{2} \cdot 4 \mathrm{H}_{2} \mathrm{O}$ in water with vigorous stirring and then to $0.5 \mathrm{~g}(0.02 \mathrm{~mol})$ of anhydrous $\mathrm{LiOH}$ in water. The resulting yellowish-cream precipitate was left for about 48 hours. Afterwards, it was filtered, and the moist solid was kept in an oven at a controlled temperature of $25^{\circ} \mathrm{C}$ to dry and recover it as a solid precursor. The reaction was depicted as shown below in equation 2 :

$$
\begin{gathered}
3 \mathrm{NaC}_{5} \mathrm{H}_{7} \mathrm{O}_{2}+3 \mathrm{H}_{2} \mathrm{O}+\mathrm{MnCl}_{2.4 \mathrm{H}_{2} \mathrm{O}+\mathrm{LiOH}} \\
\rightarrow \mathrm{LiMn}\left(\mathrm{C}_{5} \mathrm{H}_{7} \mathrm{O}_{2}\right)_{3}+2 \mathrm{NaCl}+\mathrm{NaOH}+7 \mathrm{H}_{2} \mathrm{O}
\end{gathered}
$$

\subsection{Thin film deposition}

The lithium manganese samples were prepared by the pyrolysis of synthesized lithium manganese acetylacetonate precursor using MOCVD deposition technique, earlier reported $[9,13,14]$. The films were deposited on sodalime glass substrates positioned on stainless steel blocks for good and uniform thermal contact. The deposition temperature and the flow rate of the carrier gas (nitrogen) were $420{ }^{\circ} \mathrm{C}$ and $2.0 \mathrm{dm}^{3} / \mathrm{min}$, respectively. The MOCVD experimental setup is shown in Fig. 1.

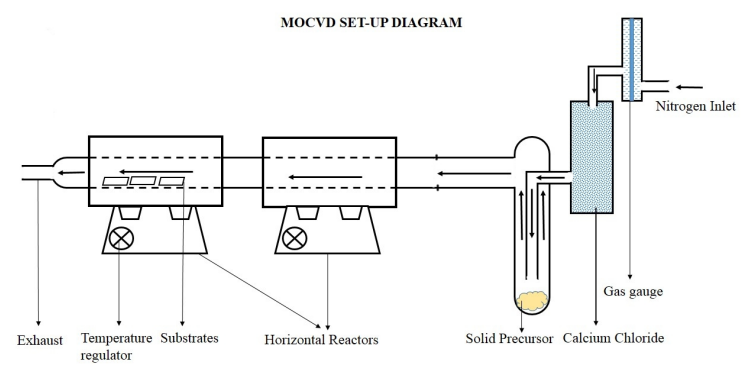

Fig. 1. The MOCVD apparatus for pyrolysis.

\subsection{Characterization of the thin films}

The ion beam analysis (IBA) facility at the Centre for Energy Research and Development, Obafemi Awolowo University, Ile-Ife, Nigeria, was used to carry out Rutherford backscattering analyses for the determination of the thickness and compositional characteristics of the films. The facility had a NEC 5SDH 1.7 MV Pelletron tandem accelerator equipped with an RF charge exchange ion source to provide proton and helium ions. The stoichiometric composition and thickness of the film samples were obtained concurrently using $2.2 \mathrm{MeV}^{4} \mathrm{He}^{+}$. Diffraction study of the films was done using X-ray mini diffractometer (Model: MD-10). The diffractometer was equipped with a high voltage source of $25 \mathrm{kV}$ delivering $\mathrm{CuK} \alpha_{\mathrm{avg}}$ radiation of wavelength $1.5418 \mathrm{~nm}$. The diffraction angle $2 \theta$ ranged from $11^{\circ}$ to $76^{\circ}$. Thermo scientific (Model: Helios Omega) UV-Vis spectrophotometer was used for the acquisition of optical transmission and absorption data of the films at normal incidence using a blank sodalime glass substrate as a reference. The morphology and the microstructural properties of the films were studied using 
Dimension Icon Atomic Force Microscopy (DI-AFM) system equipped with ScanAssyst ${ }^{\circledR}$ imaging and Nanoscope ${ }^{\circledR}$ software, located at the Department of Physics, University of Pretoria, Hatfield, Pretoria, South Africa. Van der Pauw four point probe method with a source current of $1 \mathrm{~mA}$ was used for the electrical conductivity measurement.

\section{Results and discussion}

\subsection{Rutherford backscattering spec- troscopy analysis}

The SIMNRA code (Version 6.06) was utilized for fitting the simulation over experimental data and the information regarding the stoichiometry and areal concentration of the films was extracted. The heavy element $\mathrm{Mn}$ and the light elements $\mathrm{Li}$ and $\mathrm{O}$ were detected via the backscattering process. The RBS spectra of the deposited $\operatorname{LiMn}_{x} \mathrm{O}_{y}$ are shown in Fig. $2 a$ and $2 b$. The thickness of the films is depicted in Fig. 2a, while the magnified scale to show the emission edge corresponding lithium is presented in Fig. 2b. Because of the lightness of lithium and oxygen compared to the energy of the incident probing ion $\left(2.2 \mathrm{MeV}^{4} \mathrm{He}^{+}\right)$, the signals coming from them are not as well resolved as that of the Mn. The film thickness was obtained in RBS unit using SIMNRA code and the value determined in atom areal density was $1112.311\left(10^{15}\right.$ atoms $\left./ \mathrm{cm}^{2}\right)$. Since the density of the deposited $\operatorname{LiMn}_{x} \mathrm{O}_{y}$ layer was not known and might differ from that of the bulk material, the area density might not be converted correctly. However, the effective composition of the deposited thin film compound, $\mathrm{Li}_{0.47} \mathrm{Mn}_{0.27} \mathrm{O}_{0.26}$, which was observed to be closer to the stoichiometry of $\mathrm{Li}_{2} \mathrm{O}$ and $\mathrm{MnO}$ mixture rather than that of $\mathrm{LiMn}_{2} \mathrm{O}_{4}$, could give a bad model for the atomic density determination. Based on the foregoing, we were not able to use the bulk density of $\mathrm{LiMn}_{2} \mathrm{O}_{4}$ for the determination of the atomic density (atoms $/ \mathrm{cm}^{3}$ ) of the deposited lithium manganese oxide thin film. Therefore, using deliberately bulk density of $\mathrm{MnO}\left(5.43 \mathrm{~g} / \mathrm{cm}^{3}\right)$ for the deposited film, a factor of 0.2193 was obtained for the conversion of $\mathrm{Li}_{0.47} \mathrm{Mn}_{0.27} \mathrm{O}_{0.26}$ area density $\left(10^{15}\right.$ atoms $\left./ \mathrm{cm}^{2}\right)$ into nanometer units, using the relation given by Chu et al. [15]. The estimated linear thickness value was $243.93 \mathrm{~nm}$. It can be observed from the RBS spectra and the obtained areal density value that the film is fairly thick. Expectedly, barring variation in other process parameters, the layer thickness is predictably an increasing function of deposition time [16]. Therefore, to deposit a film with lower thickness, the deposition time should be reduced.

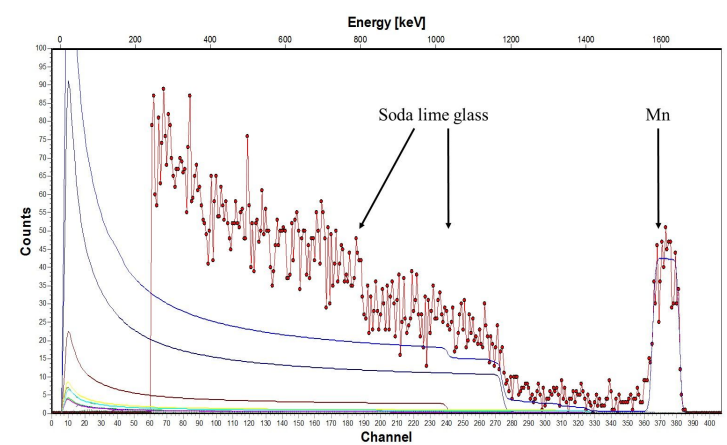

(a)

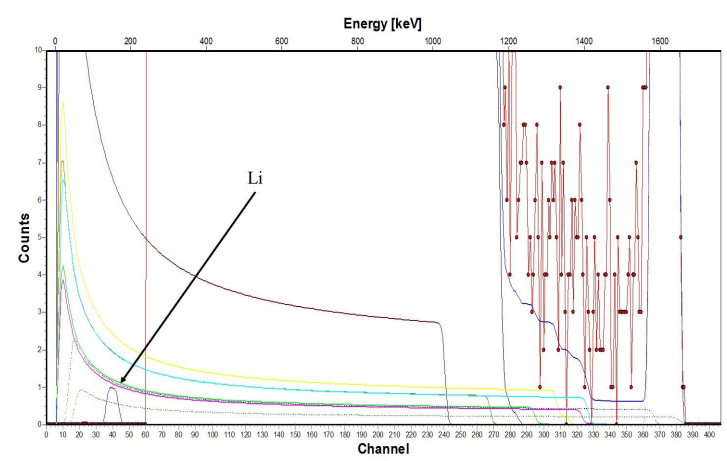

(b)

Fig. 2. (a) RBS spectra for LiMnxOy thin film showing thickness of the Mn film; (b) Enlarged RBS spectra for $\mathrm{LiMn}_{\mathrm{x}} \mathrm{O}_{\mathrm{y}}$ film showing the presence of lithium.

\subsection{Microstructural analysis}

X-ray diffraction patterns of the deposited lithium manganese oxide thin film and the precursor are shown in Fig. 3. It is observed that the precursor is crystalline, thus, exhibits well resolved peaks at low 2 theta region, $21.65^{\circ}, 25.82^{\circ}$ and $30.75^{\circ}$, which correspond to the following planes (1 $\left.\begin{array}{lll}1 & 0 & 1\end{array}\right)$ and (2 200 ) attributed to $\mathrm{MnO}_{2}$ and $\mathrm{MnO}$ 
in previous studies $[17,18]$. The spectra obtained for the deposited $\mathrm{Li}_{0.47} \mathrm{Mn}_{0.27} \mathrm{O}_{0.26}$ film show a broad or diffuse peak in the lower 2 theta region which might be an indication of a nanocrystalline structure [17]. But the absence of identifiable welldefined peaks in the spectra gives more indication for regarding the deposited $\mathrm{Li}_{0.47} \mathrm{Mn}_{0.27} \mathrm{O}_{0.26}$ thin film as amorphous. The amorphous nature observed may not be unconnected with the nature of the glass substrate in conjunction with other possible factors, such as film thickness and deposition temperature. The crystallinity of deposited films is usually determined by the complex interaction between the substrate and the developing film [19].

The 2D and 3D AFM images of the film are shown in Fig. $4 \mathrm{a}$ and $4 \mathrm{~b}$, respectively. The film microstructure is observed to be well distributed on the substrate and intensely dense in nature with no observable pores. In addition, the presence of few scattered white phases interspersed in the layer can be seen. The representative highly magnified 3D image of the film shows uniformly arranged crystallites with maximum surface roughness value of $78.6 \mathrm{~nm}$. Previous results [19] have shown that moderate surface roughness with consequent greater surface area does enhance electrode-electrolyte interactions. The average crystallite size as observed from the 3D AFM image is about $0.25 \mu \mathrm{m}$ with some bigger grains interspersed within thin structure. The thickness and the dense film microstructure observed were influenced by the chemical vapour deposition (CVD) technique used. Unlike the physical vapour deposition (PVD) method, CVD procedures are diffusive processes [20], which means the deposition covers the entire available surface area. Also because the CVD temperatures are comparatively higher, the adatoms have surface mobilities, which improves step coverage. The electrical characterization carried out using van der Pauw four point probe gave the sheet resistance, (Rs) and resistivity, $(\rho)$ values of the lithium manganese oxide thin films as $3.63 \times 10^{5} \Omega / \mathrm{sq}$ and $4.9 \Omega \cdot \mathrm{cm}$, respectively, at room temperature. Electrical properties studied for related material, $\mathrm{K}_{1.33} \mathrm{Mn}_{8} \mathrm{O}_{16}[21,22]$ prepared electrolytically at $505{ }^{\circ} \mathrm{C}$ showed them to be semiconducting with resistivity values of $33 \Omega \cdot \mathrm{cm}$ at $21{ }^{\circ} \mathrm{C}$ and $2.5 \Omega \cdot \mathrm{cm}$ at $80{ }^{\circ} \mathrm{C}$. The fairly lower resistivity shows the influence of the dense nature of the film and highly reactive $\mathrm{Li}$ in the film matrix. This indicates that the films possess good semiconducting properties. The value of sheet resistance is within the standard range of $10^{5}$ to $10^{6} \Omega / \mathrm{sq}$ as earlier reported [23].

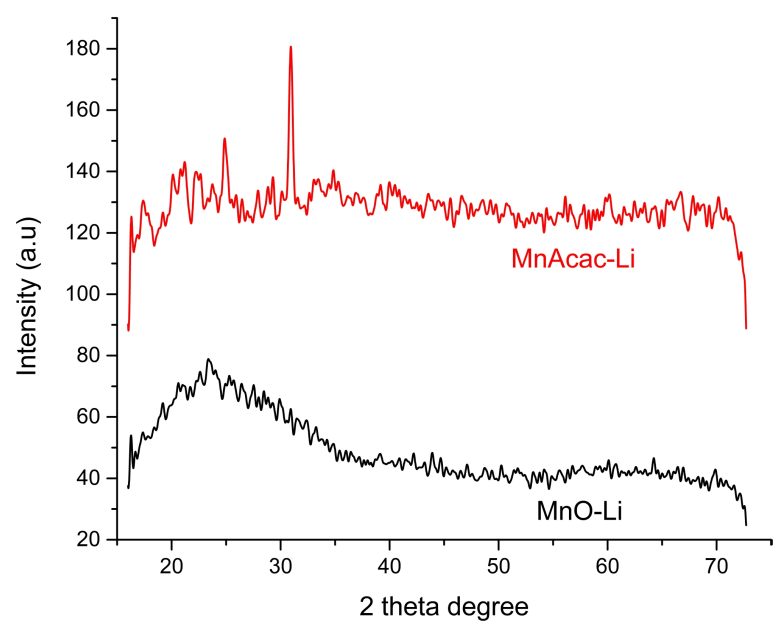

Fig. 3. X-ray diffraction patterns of lithium manganese oxide precursor and the thin film.

\subsection{UV-Vis spectrophotometry studies}

The absorbance and the band gap analysis are presented in Fig. 5. From the figures, it is shown that the thin film has relatively high transmittance of up to $50 \%$ starting towards the edge of the visible region and maintaining the behaviour well up to the NIR region. Conversely, as expected, the adsorption is low in the visible region compared with the behaviour in the UV and the onset of the visible region. As shown from the spectra and characteristics of amorphous films, a broad absorption edge is observed at about $\lambda=556 \mathrm{~nm}$. One main distinction between amorphous and crystalline solids is the presence of a sharp well-defined lattice absorption edge $\mathrm{E}_{\mathrm{g}}$ for crystalline solids, whereas, in amorphous materials, the absorption edge is not well defined [24]. In order to study the effect of addition of lithium, especially on the optical properties of the deposited film, an ordinary $\mathrm{MnO}$ thin film was prepared using the same conditions for 


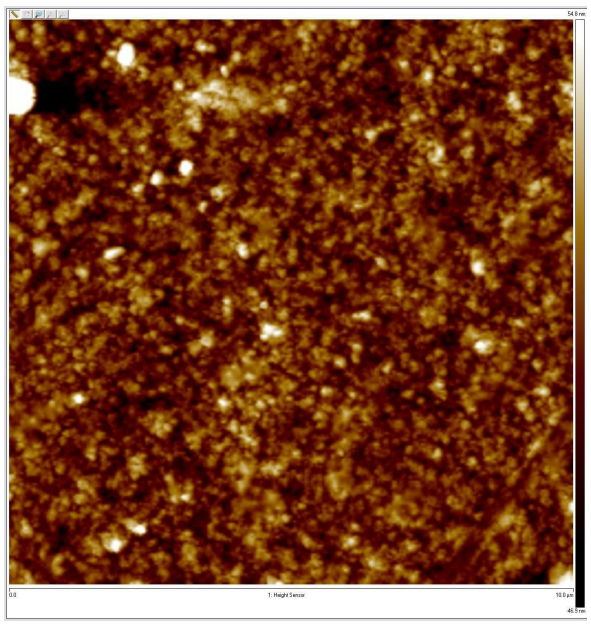

(a)

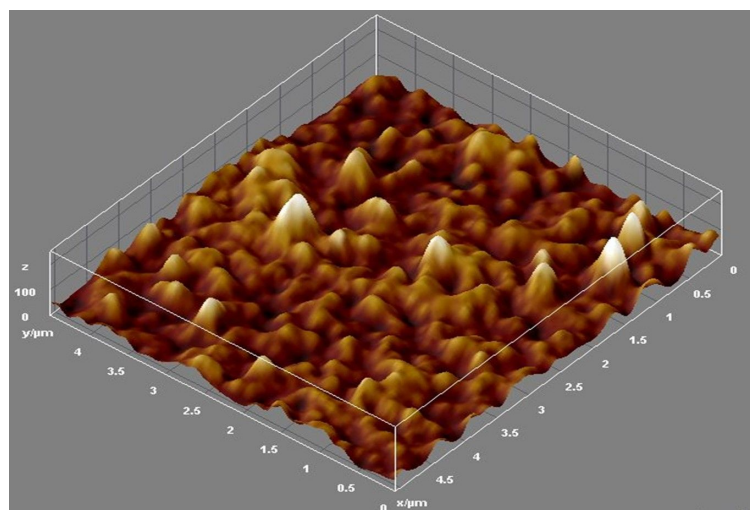

(b)

Fig. 4. (a) AFM image and (b) 3D AFM image of lithium mangnese oxide thin film.

optical characteristics comparison. Fig. 5b shows the transmittance spectra of the deposited lithium manganese oxide and ordinary deposited $\mathrm{Mn}_{\mathrm{x}} \mathrm{O}_{\mathrm{y}}$ thin films. It is observed that the addition of lithium into the $\mathrm{MnO}$ structure has caused a significant shift in the absorption edge. The edge is, thus, shifted towards higher wavelengths. The presence of lithium ion in $\mathrm{Mn}_{\mathrm{x}} \mathrm{O}_{\mathrm{y}}$ could have also contributed to the lowering of the transmission as observed in the percentage transmittance of the film in the visible and NIR regions, most probably due to the presence of more scattering centres in the film [25]. The thickness and the roughness of the surface of the film as observed in AFM images (Fig. 4a and 4b) are additional physical parameters that influenced the transmittance of the samples. The optical absorption coefficient $(\alpha)$ of the films was determined from the optical transmission data acquired. The optical bandgap of the films was evaluated from the plot of $(\alpha \mathrm{hv})^{2}$ versus photon energy (hv) using the Tauc's relation [26]:

$$
(\alpha h v)=B\left(h v+E_{g}\right)^{r}
$$

where B is a parameter that depends on the transition probability, $\mathrm{E}_{\mathrm{g}}$ is the optical bandgap energy of the material and $\mathrm{r}$ is an index that characterizes the optical absorption process. In this study, $r$ is equal to $1 / 2$ for direct allowed transition. Fig. 5c shows the plot of the square of absorption coefficient, $\alpha^{2}$ against energy, E. The plot gives the direct band gap of the lithium manganese oxide thin film of $2.55 \mathrm{eV}$, while that of manganese oxide is $2.83 \mathrm{eV}$. From the $\mathrm{E}_{\mathrm{g}}$ values obtained, it is observed that the presence of lithium in the thin film matrix lowered the energy band gap.This indicates a narrowing of the forbidden gap due to the inclusion of lithium ions in the $\mathrm{MnO}$ system. This might be due to certain structural evolution occurring in the material with changing composition. The Li content may have some localized states in the deep energy levels to induce a decrease in the energy gap [27].

\section{Conclusions}

Metal organic chemical vapor deposited lithium manganese oxide thin films have been successfully prepared using lithium manganese acetylacetonate as a single solid source precursor. XRD patterns indicated presence of mixed phases of $\mathrm{MnO}$ and $\mathrm{MnO}_{2}$ in the precursor, while a broad peak pattern was obtained for the deposited film, showing amorphous nature of the film. Optical analyses indicated a relatively high transmission in the visible and near infrared range. A significant shift in the broad lattice absorption edge was observed when compared with $\mathrm{MnO}$ thin film. The shift was due to the presence of lithium in the $\mathrm{Li}_{0.47} \mathrm{Mn}_{0.27} \mathrm{O}_{0.26}$ structure. It was shown that lithium manganese oxide thin films with desired thickness, good uniformity, enhanced optical and electrical properties could be deposited from metal organic single solid precursor using simple and efficient metal-organic chemical vapor deposition technique. 


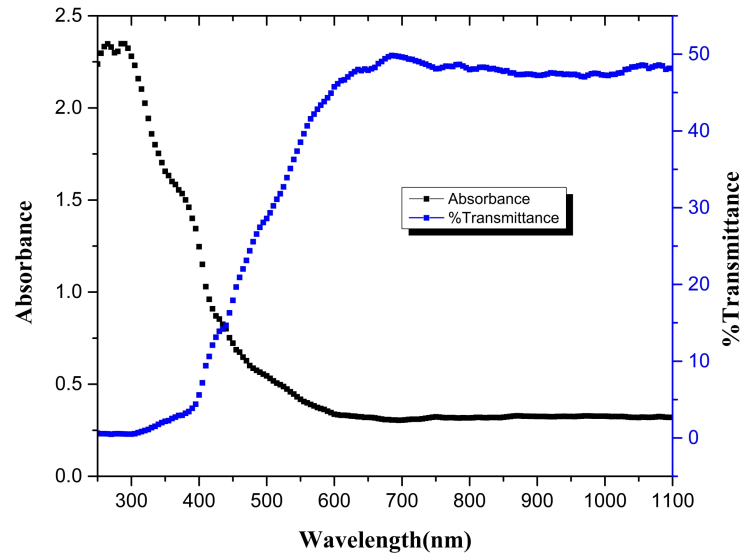

(a)

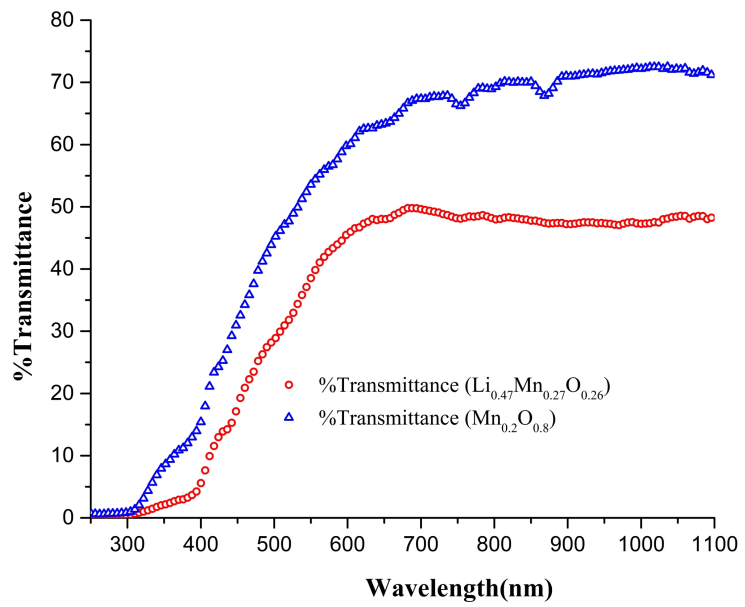

(b)

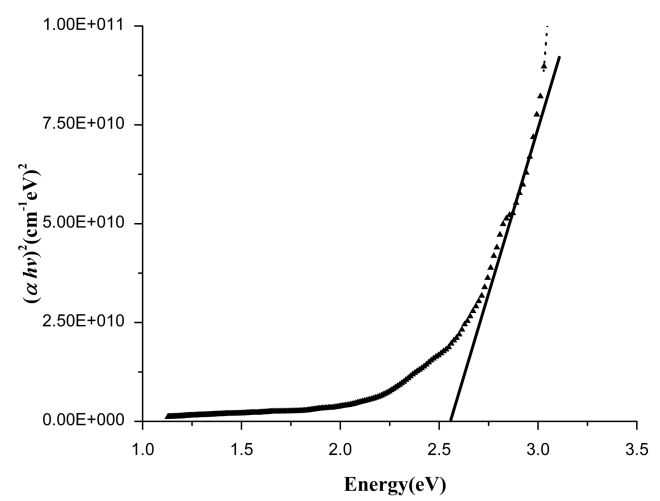

(c)

Fig. 5. (a) plot of absorbance and transmittance against wavelength for lithium manganese oxide thin film, (b) plot of transmittance against wavelength for $\mathrm{Li}_{0.47} \mathrm{Mn}_{0.27} \mathrm{O}_{0.26}$ and $\mathrm{Mn}_{0.2} \mathrm{O}_{0.8}$ thin films, (c) plot of $(\alpha \mathrm{hv})^{2}$ against energy for lithium manganese oxide thin film.

\section{References}

[1] Flores-Gonzalez M.A., Villanuevalbanez M. DIAZDE L.S.J.L., SMCSYV, 19 (2006), 23.

[2] Xu X.H., Jiang X.F., Li X.L., Chen Y., Gehring G. A., Appl. Surf. Sci., 258 (2008), 4956.

[3] Asogwa P.U., Ezugwu S.C., Ezema F.I., EKWeAlor A.B.C., EzeKoye B.A., Osuji R.U., J. Optoelectron. Adv. M., 11 (2009), 940.

[4] Schroder D.K., Semiconductor Material and Device Characterization, John Wiley \& Sons, New York, 2006.

[5] AJaYi E. O.B., M. Sc. Thesis, Urbana Illinois, 1970.

[6] Mizushima K., Jones P.C., Wiseman P.J., GoodENOUGH J.B., Mater. Res. Bull., 15 (1980), 783.

[7] Antaya M., Dahn J.R., Preston J.S., Rossen E., REIMERS J.N., J. Electrochem. Soc., 140 (1993), 475.

[8] Wang B., Bates J.B., Hart F.X., Sales B.C., Zhur R.A., Robertson J.D., J. Electrochem. Soc., 143 (1996), 3203.

[9] Eleruja M.A., Adedeji A.V., Egharevba G.O., Lambi J.N., AKanni M.S., Jeynes C., AJAYi E. O.B., Opt. Mater., 20 (2002), 119.

[10] Fischer J., Adelhelm C., Bergfeldt T., Chang K., Ziebert C., Leiste H., Stüber M., Ulrich S., Music D., Hallstedt B., Seifert H.J., Thin Solid Films, 10 (2012), 1016.

[11] Arun P., Vaishali P., Dong W.S., Ji-Won C., Dong-Soo P., SeOK-Jin Y., Mater. Res. Bull., 43 (2007), 13.

[12] REX X., J. Met. (Jom-E), 49 (1997), 10.

[13] Ajayi O.B., Osuntola O.K., OJo I.A.O., Jeynes C., Thin Solid Films, 248 (1994), 57.

[14] Eleruja M.A., Adedeji A.V., OJo I.A.O., DJebah A., Osasona O., Aladekomo J.B., Ajayi E. O.B., Opt. Mater., 10 (1998), 257.

[15] ChU W.K., Mayer J.W., Nicholet M.A., Backscattering Spectroscopy, Academic Press, London, 1978.

[16] Malinsky P., Slepicka P., Hnatowicz V., SvorCIK V., Nanoscale Res. Lett., 7 (1) (2012), 241.

[17] Jin S.W., Wadley H. N.G., J. Vac. Sci. Technol. A, 26 (2008), 1.

[18] Thiagarajan S., Hsuan T.H., Chen S.-H., Int. J. Electrochem Sci., 6 (2011), 2235.

[19] Moon H.-S., Ji K.-S., PARK J.-W., J. Korean Phys. Soc., 40 (2002), 22.

[20] Franssila S., Thin-film Growth and Structure, in: Franssila S., Introduction to Microfabrication, John Wiley \& Sons, Singapore, 2004, p. 77.

[21] Strobe X.P., Vicat J., Qui D.T., J. Solid State Chem., 55 (1984), 67.

[22] Vicat J., Fanchon E., Strobel P., Qui D.T., Acta Crystallogr. B, 42 (1986), 162.

[23] Strobel P., Charenton J.C., Mater. Res. Bull., 28 (1996), 93.

[24] Altaf M., Chaudhry M.A., J. Korean Phys. Soc., 36 (2000), 265.

[25] Ajenifuja E., Fasasi A.Y., Osinkolu G.A., T. Indian Ceram. Soc., 71 (2012), 181. 
[26] Tauc J., Grigorovici R., Vancu A., Phys. Status Solidi, 15 (1966), 627.

Received 2014-12-08

[27] Jonscher A.K., Thin Solid Films, 1 (1967), 213.

Accepted 2015-08-25 